\title{
Correlation between behaviour during labour and blood plasma concentrations of vasopressin in goats*
}

\author{
K. Olsson ${ }^{1}$, J. Stein and S. Thorén \\ Department of Animal Physiology, Swedish University of Agricultural Sciences \\ Box 7011, S - 75007 Uppsala, Sweden
}

\begin{abstract}
Buprenorphine was given intravenously to goats to study if it dampens pain and the increase in plasma vasopressin concentration during labour. Seven goats were given buprenorphine $(0.005$ $\mathrm{mg} / \mathrm{kg}$ ) and 6 goats were given saline. The expressions of pain were evaluated on a Visual Analogue Scale from 0-10 (mild to severe pain) and the vasopressin concentration was measured with a radioimmunoassay. The pain expressions did not differ between the goats that received the drug and the controls. However, the expressions of pain were correlated to the vasopressin concentration, giving support to the idea that the vasopressin concentration is affected by pain.
\end{abstract}

KEY WORDS: buprenorphine, goat, labour, pain, parturition, vasopressin

\section{INTRODUCTION}

Pain relief in animals has achieved increasing interest over the last decades. However, the opinions differ concerning how to assess pain in animals and few studies correlate physiological variables with evaluations of pain (Conzemius et al., 1997). Labour is a natural event associated with pain. Apart from the hormones known to be directly involved in the birth process in goats, blood plasma vasopressin concentrations increase to high levels at the birth of the first kid and then decline (Hydbring et al., 1999). The reason for this is not clear, but it was suggested that the high levels were correlated to the pain during the phase of cervical dilatation.

Buprenorphine is a partial opioid kappa-receptor agonist, which is used for pain relief. We hypothetized that buprenorphine would dampen the expressions of pain and the rise in plasma vasopressin concentration during labour.

\footnotetext{
${ }^{*}$ Supported by the Swedish Research Council-Medicine, Project No. 3392

${ }^{1}$ Corresponding author: e-mail: kerstin.olsson@afys.slu.se
} 


\section{MATERIAL AND METHODS}

Seven goats were given buprenorphine and six goats isotonic saline. Goats in the buprenorphine group were 1-4 years old and weighed $58 \pm 4 \mathrm{~kg}$ at parturition. Goats in the saline group were 1-4 years old and weighed $61 \pm 6$ $\mathrm{kg}$. In each group two goats had singletons, one goat in the saline group had three kids and all other goats had twins. They were kept indoors in two pens at a room temperature of $17 \pm 1^{\circ} \mathrm{C}$. One to four days before parturition, they were moved to a box where they could still see and hear the other goats. The Local Ethical Committee in Uppsala, Sweden approved the care of the animals and the experimental design.

Buprenorphine (Temgesic ${ }^{\circledR}$, Meda Sverige AB, Gothenburg, Sweden; 0.005 $\mathrm{mg} / \mathrm{kg}$ ) or isotonic saline were given intramuscularly at random when the first abdominal contractions were observed. This turned out to be $104 \pm 30 \mathrm{~min}$ before birth of the first kid. Blood samples were withdrawn from a catheter inserted under local anaesthesia (when was this inserted?). Blood samples were taken according to the phases of labour: 1. first labour pains (restlessness, kicking, tailflick); 2. synchronized abdominal contractions: 3 . first amniotic membrane: 4 . feet of the kid: 5 . head; 6 . first kid born. The vasopressin concentration was analysed by radioimmunoassay after extraction with aceton and petroleum benzene. The lower detection limit was $0.5 \mathrm{pmol} / \mathrm{L}$. Buprenorphine was analysed in sample 2, which was taken immediately before the injection was given, and in samples 4 and 6 using an EIA assay with the lowest detectable value of $0.16 \mathrm{ng} / \mathrm{ml}$ (AnaLytics Inc., Gaithersburg, USA). Only one person (KO) knew which substance the goats were given. The behaviour was registered continuously from phase 3 to 6 by the other two authors. Direct observations and video film recordings were used to rank the pain of each goat on a Visual Analogue Scale (VAS). Each goat's position on the scale was mainly based on the frequency and intensity of vocalization and the duration of phases 3-6 (Table 1), but number of tailflicks, changes of posture, and stretching the head backwards were also taken into account in the evaluation of the overall impression of pain.

\section{RESULTS}

The buprenorphine analyses revealed zero levels in the control sample in 6 of the goats and $0.16 \mathrm{ng} / \mathrm{ml}$ in one goat. The drug was undetectable in 3 of the goats and between 0.18 to $0.38 \mathrm{ng} / \mathrm{ml}$ in the other 4 animals. There was no significant difference in the goats' expressions of pain between the groups (Table 1). 
Table 1. Frequency (number/min) and intensity of vocalization (scale from 1 to 13 where 13 denotes the loudest) and duration of phases 3 to 6 . Goats 1-7 were given buprenorphine and goats 8-13 were given isotonic saline

\begin{tabular}{rcccc}
\hline \multirow{2}{*}{ Goat } & Age & \multicolumn{2}{c}{ Vocalization } & $\begin{array}{c}\text { Duration, min } \\
\text { sample 3-6 }\end{array}$ \\
\cline { 2 - 4 } & years & frequency & intensity & 7 \\
2 & 3 & 5.14 & 6 & 21 \\
3 & 2 & 3.00 & 9 & 19 \\
4 & 1 & 5.05 & 11 & 10 \\
5 & 2 & 1.89 & 6 & 5 \\
6 & 3 & 1.60 & 3 & 9 \\
7 & 4 & 0.11 & 3 & 10 \\
8 & 1 & 8.55 & 8 & 3 \\
9 & 4 & 0.67 & 2 & 10 \\
10 & 1 & 7.67 & 12 & 2 \\
11 & 2 & 10.67 & 9 & 14 \\
12 & 3 & 0.06 & 1 & 4 \\
13 & 1 & 10.50 & 12 & 2 \\
\hline
\end{tabular}

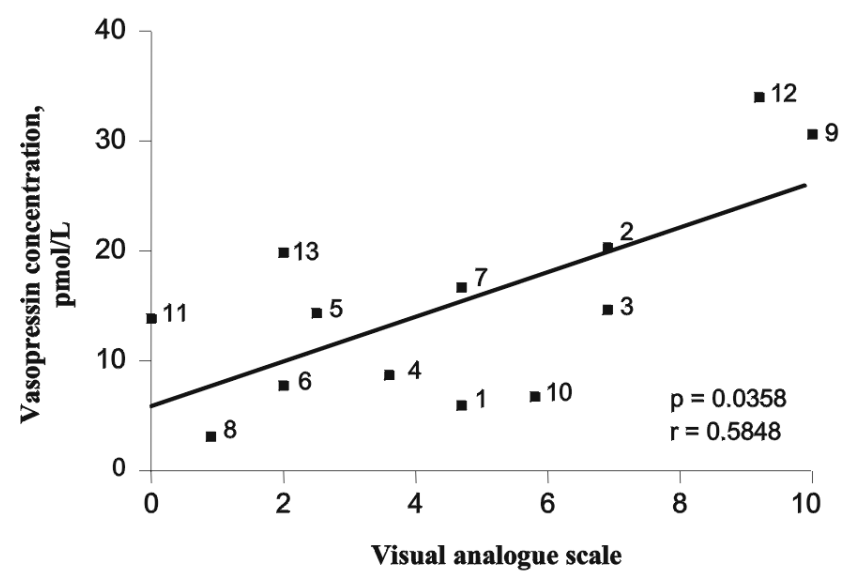

Figure 1. Relationship between the mean plasma vasopressin concentrations of samples 3-6 during labour against scores on the VAS. The numbers correspond to the same goats as in Table 1

The plasma vasopressin concentration was highest in samples 3-6 with no significant difference between the groups. Therefore, we studied the relationship between the pain score on the VAS and the vasopressin concentration regardless of treatment (Figure 1). 


\section{DISCUSSION}

The present data, though on a rather low number of animals, showed no evidence that buprenorphine relieved pain during labour in goats. The dose was calculated to give pain relief for at least $6 \mathrm{~h}$ (Roughlan and Flecknell, 2002). The results indicate that the recommended dose was too low.

There was a correlation between the plasma vasopressin concentration and the score on the VAS scale, which supports the hypothesis that the vasopressin concentration is correlated to labour pain in goats. Part of the reason may be that vasopressin augments the forceful uterine contractions caused by oxytocin as earlier suggested by Åkerlund et al. (1995).

\section{CONCLUSIONS}

No evidence was found for pain-relieving effects of buprenorphine on labour pain in these goats. The correlation between the pain expression and the plasma vasopressin concentration supports the idea that vasopressin is related to the pain of labour in goats.

\section{REFERENCES}

Åkerlund M., Melin P., Maggi M., 1995. Potential use of oxytocin and vasopressin V1a antagonists in the treatment of preterm labour and primary dysmenorrhea. Advan. Exp. Med. Biol. 395, $595-600$

Conzemius M.G., Hill C.M., Sammarco J.L., Perkowski S.Z., 1997. Correlation between subjective and objective measures used to determine severity of postoperative pain in dogs. J. Amer. Vet. Med. Assn. 210, 1619-1622

Hydbring E., Madej A., MacDonald E., Drugge-Boholm G., Berglund B., Olsson K., 1999. Hormonal changes during parturition in heifers and goats are related to phases and severity of labour. J. Endocrinol. 160, 75-85

Roughan J.V., Flecknell P.A., 2002. Buprenorphine: A reappraisal of its antinociceptive effects and therapeutic use in alleviating post-operative pain in animals. Lab. Animals 36, 322-343 